\title{
E्己̌ruAáo Desafios e Dificuldades na Implementação do Programa Mais Educação: percepção dos atores das escolas
}

\author{
Antonio Jorge Gonçalves Soares' \\ Fabio Brandolin" \\ Daniela Patti do Amaral'
}

'Universidade Federal do Rio de Janeiro (UFRJ), Rio de Janeiro/RJ - Brasil

"Instituto Benjamin Constant (IBC), Rio de Janeiro/RJ - Brasil

RESUMO - Desafios e Dificuldades na Implementação do Programa Mais Educação: percepção dos atores das escolas. O presente artigo tem o objetivo de investigar a implementação do Programa Mais Educação (PME) a partir da percepção dos atores que tomam decisões cotidianas nas escolas para dar corpo aos objetivos dessa política indutora do governo federal. A pesquisa foi conduzida em 6 escolas da rede municipal de Petrópolis-RJ e contou com a participação de 33 entrevistados. Os resultados indicam que as escolas enfrentam dificuldades de estabelecer parcerias com outras instituições para o desenvolvimento das atividades do programa, os gestores valorizam o PME por seu caráter de assistência e apoio às famílias e os monitores, apresentam frágeis vínculos com o programa por conta do baixo valor da ajuda de custo, colocando em xeque o caráter voluntário da participação. Palavras-chave: Educação Integral. Implementação. Voluntários. Escola de Tempo Integral.

ABSTRACT - Challenges and Difficulties in Implementing the Mais Educação Program: perception of the schools' actors. The aim of this paper was to investigate the implementation of Mais Educação Program - PME by means of interviews with individuals in charge of its development at the school level: principals, PME coordinators, PME monitors. The research was conducted in six schools of Petropolis/RJ municipal system with 33 participants. The results indicate that schools face obstacles concerning the establishment of partnerships with other institutions for the development of the program's activities; the school principals value PME for its assistance character and the support provided to families; and the monitors present weak links with the program due to the low value of the allowance. All these aspects challenge the volunteer nature of their participation.

Keywords: Full-time Education. Implementation. Volunteers. Full-time School.

Educação \& Realidade, Porto Alegre, v. 42, n. 3, p. 1059-1079, jul./set. 2017. 1059 http://dx.doi.org/10.1590/2175-623660490 
Desafios e Dificuldades na Implementação do Programa Mais Educação

\section{Introdução}

O Programa Mais Educação (PME) iniciou em 2007 amparado por dispositivos legais que fixaram objetivos de ampliação da jornada escolar. Essa proposta surgiu com abrangência nacional visando a indução da educação em tempo integral/educação integral no sistema escolar público brasileiro com os seguintes objetivos: estender a jornada escolar e melhor atender às necessidades de cada aluno; reduzir a reprovação e a distorção idade/série; combater o trabalho infantil, a exploração sexual e outras formas de violência; desenvolver habilidades cognitivas; promover a cultura e a prática esportiva; aproximar famílias, escola e comunidade. Sua estruturação se deu a partir do conceito de intersetorialidade na medida em que participaram da criação do programa os ministérios da Educação, da Cultura, do Desenvolvimento social e combate à fome e o do Esporte. A operacionalização dessa política de indução foi realizada pela Secretaria de Educação Básica (SEB), através do Programa Dinheiro Direto na Escola (PDDE) do Fundo Nacional de Desenvolvimento da Educação (FNDE) (Brasil, 2014a). O PDDE criou uma linha de comunicação direta do governo federal com as unidades escolares e permitiu a estas certa autonomia para gerir os recursos para implementar as atividades do PME e, ao mesmo tempo, equipar a escola com materiais e equipamentos básicos ao desenvolvimento de suas atividades.

O PME está organizado pedagogicamente em sete macrocampos que oferecem diferentes atividades/oficinas para as escolas urbanas e rurais, de acordo com o Manual Operacional de Educação Integral (Brasil, 2014a): 1- acompanhamento pedagógico; 2- comunicação; uso de mídias e cultura digital e tecnológica; 3- cultura, artes e educação patrimonial; 4- educação ambiental, desenvolvimento sustentável e economia solidária e criativa/educação econômica (educação financeira e fiscal); 5- esporte e lazer; 6- educação em direitos humanos; 7promoção da saúde. Desses macrocampos são formadas as turmas das oficinas que devem ter até 30 alunos, com exceção da turma de orientação de estudos e leitura que deverá ser constituída por até 15 alunos. As turmas podem ser formadas sem obedecer necessariamente a homogeneização das faixas etárias e dos anos escolares dos alunos atendidos, considerando as características das atividades de cada oficina. Um dos critérios do PME é que cada escola atenda, preferencialmente, $100 \mathrm{alu}$ nos, entretanto, esse critério se flexibiliza para as escolas que não possuem este quantitativo no seu quadro total de matrículas (Brasil, 2014a).

$\mathrm{O}$ MEC recomenda que selecionem as atividades de acordo com sua proposta pedagógica, totalizando 4 atividades divididas entre os diferentes macrocampos. As atividades podem ser realizadas dentro ou fora da área da escola, frequentemente estabelecendo parcerias com organizações da sociedade civil ou entidades públicas/privadas. Dentre estas 4 atividades, a única obrigatoriedade é de oferecer a atividade de orientação de estudos e leitura, presente no macrocampo acompanhamento pedagógico (Brasil, 2014a).

1060 Educação \& Realidade, Porto Alegre, v. 42, n. 3, p. 1059-1079, jul./set. 2017. 
Diante da precariedade da estrutura física das escolas brasileiras (Barbosa, 2009) e pela concepção do programa que pretende estreitar as relações entre a escola e a sociedade, o PME orienta que as escolas busquem parcerias com instituições ou entidades, públicas ou privadas, para o desenvolvimento das atividades. Essa dinâmica se torna necessária para o funcionamento e gestão do programa, pois, o PME não estimou em suas edições iniciais previsão orçamentária para o investimento em melhorias ou ampliações da infraestrutura escolar.

O desenho do PME estrutura o funcionamento das oficinas com a mão de obra do monitor voluntário de quem não se exige formação qualificada específica. De acordo com o conceito internacional do voluntariado, o monitor voluntário seria, em tese, um cidadão que doa seu tempo atuando ativamente na construção de uma sociedade mais justa e solidária. Todavia, o Manual Operacional de Educação Integral (2014a) indica que o monitor deverá ser, preferencialmente, estudante de algum curso em nível superior com formação equivalente a sua área de atuação. A palavra "preferencialmente" orienta a gestão escolar a selecionar graduandos como monitores, mas essa orientação não se constitui em barreira para atrair qualquer mão de obra para atuar no programa.

O monitor no PME recebe $\mathrm{R} \$ 80,00$ (oitenta reais) por cada turma nas escolas urbanas e $\mathrm{R} \$ 120$ (cento e vinte reais) por cada turma nas escolas rurais. Os monitores assinam um termo de compromisso, amparado nos dispositivos legais do voluntariado (Brasil, 1998), informando sobre a característica voluntária do seu trabalho no PME. Esses valores recebidos por cada turma são considerados ressarcimento das despesas com alimentação e transporte. A coordenação desses monitores deve ser realizada por um professor comunitário, com matrícula de 40 horas na rede de ensino, preferencialmente que "[...] será o responsável pedagógico e administrativo do programa, e seus custos referem-se à contrapartida oferecida pela Entidade Executora (EEx)" (Brasil, 2014a, p. 18). No âmbito local, a gestão e execução do PME são realizadas pelas Secretarias de Educação que receberão apoio intersetorial de órgãos públicos de diversos setores como do esporte, da cultura, da ciência e tecnologia, do meio ambiente e da juventude. Cada secretaria de educação, estadual ou municipal, irá nomear um funcionário responsável com a função de coordenar o PME nas escolas participantes de sua rede de ensino.

O PME vai ao encontro da atual conjuntura que tem a escola de tempo integral como um tema de destaque na agenda da educação brasileira, principalmente, após a aprovação do Plano Nacional de Educação (Brasil, 2014b). O PNE, em sua Meta 6, propõe oferecer a educação em tempo integral para no mínimo 50\% das escolas públicas do Brasil, atendendo pelo menos $25 \%$ dos alunos da educação básica. De acordo com as projeções extraídas do documento Conheça as 20 metas do PNE da Câmara dos Deputados, em 2013, existiam 3,4 milhões de alunos matriculados na educação em tempo integral, gerando um gasto de 2 bilhões de reais e totalizando 0,04\% do Produto Interno Bruto (PIB). Com o atendimento a Meta 6, os números saltariam dos 3,4 milhões para 11 
Desafios e Dificuldades na Implementação do Programa Mais Educação

milhões de matrículas em educação em tempo integral, aumentando os gastos de 2 bilhões para 32 bilhões de reais, totalizando $0,66 \%$ do PIB (Piovesan, 2014). Estes números traduzem a necessidade de investigarmos e compreendermos como o PME vem sendo apropriado e gerido pelas escolas que participam do programa.

Diante das atuais demandas legais e das políticas de indução para ampliação do tempo escolar nos sistemas públicos de educação, o presente artigo tem o objetivo de investigar a implementação do PME a partir da percepção dos atores que tomam decisões cotidianas nas escolas para dar corpo aos objetivos dessa política indutora do Governo Federal. Estudar a implementação significa observar, a partir da ponta que se destina a política, como decorrem os processos de gestão, interpretação e materialização dos programas que se destinam aos beneficiados. Dyer (2012) argumenta que conceber as políticas educacionais, em países em desenvolvimento, se torna mais prestigioso que monitorar e avaliar os efeitos da implementação das políticas, na medida em que é prática comum e quase universal o descaso dado às questões de implementação, pois,

[...] os responsáveis por essas políticas "tendem a supor que as decisões de promover mudanças automaticamente resultarão na alteração das políticas ou do comportamento das instituições" (Grindle; Thomas, 1991, p. 121), ao invés de planejarem cuidadosamente as etapas de implementação que se seguem à decisão de se iniciar a mudança (Dyer, 2012, p. 472).

Segundo Lotta (2010), ao estudar as produções sobre implementação, a atenção para o trabalho dos burocratas surge com especial destaque, principalmente em relação aos profissionais da ponta do sistema, aqueles que estão em contato direto com a população, isto é, "analisar a política pública com base na ação dos seus implementadores, contrapondo-se às pesquisas dedicadas a analisar apenas processos decisórios/decisores e gestores de esferas e órgãos centrais" (Martins, 2013, p. 290). Como exemplo destes profissionais, podemos citar os professores, os policiais, os médicos, os enfermeiros e outros que se tornam funcionários responsáveis por fazer com que as políticas públicas voltadas para a educação, segurança e saúde, respectivamente, cheguem até a população. Lipsky (1980) foi um dos primeiros a levantar a necessidade de analisar a ação destes funcionários no cotidiano para entender o sucesso ou o fracasso das políticas e cunhou o termo Street-Level bureaucracy ou burocracia do nível de rua para definir a atuação profissional destes trabalhadores responsáveis pelo contato direto com os cidadãos. Tais agentes, por serem os implementadores concretos da política, representam o estado de forma concreta e possuem certo grau de poder discricionário ao interpretar as políticas e agir em nome do estado.

Na mesma direção, Perez (2010, p. 1183) indica a necessidade de investigar sob que condições as diversas políticas educacionais são implementadas e como elas funcionam. Segundo o autor,

1062 Educação \& Realidade, Porto Alegre, v. 42, n. 3, p. 1059-1079, jul./set. 2017. 
[...] a literatura especializada tem chamado a atenção para as contribuições proporcionadas por esse tipo de pesquisa: 1) visam corrigir o curso das ações, fornecendo subsídios aos implementadores durante o curso da política, em razão de suas características de policy oriented; 2) buscam ampliar a efetividade do processo de decisão dos programas públicos; 3) contribuem para ampliar a accountabilitydos programas; 4) ampliam a integração dos corpos administrativo, político e comunidade, fundamentais para a mudança do desempenho educacional.

Neste sentido, nossa pesquisa dedicou-se a investigar como os burocratas do nível de rua envolvidos com o PME estão conduzindo a implementação do programa em suas escolas. Como afirmado por Mainardes (2006, p. 50), se deve realizar uma "interpretação ativa" daquilo que os profissionais fazem quando relacionam os textos da política à prática. Segundo o autor, "isso envolve identificar processos de resistência, acomodações, subterfúgios e conformismo dentro e entre as arenas da prática, e o delineamento de conflitos e disparidades entre os discursos nessas arenas" (Mainardes, 2006, p. 50).

\section{Diagnósticos Justificadores do PME}

Em se tratando da qualidade da educação pública no Brasil, ainda não avançamos qualitativamente de forma efetiva quando comparamos nosso sistema educacional com os dos países mais bem colocados nas avaliações internacionais. Nos resultados do Programa Internacional de Avaliação de Estudantes (PISA) de 2012, o Brasil aparece na 58 posição entre 65 países avaliados (OCDE, 2012). Todavia, avançamos na universalização do ensino fundamental com a expansão do sistema educacional público brasileiro nas últimas duas décadas.

Se, por um lado, são louváveis os esforços em direção à universalização da educação básica, por outro, fica a questão que a expansão implementada foi conduzida a partir de um modelo escolar pensado e construído para poucos. Cavaliere (2002) esclarece que a escola fundamental brasileira "tinha a função precípua da instrução escolar, e sua ação social era uma expansão linear dos processos integradores da comunidade sociocultural homogênea que a ela tinha acesso" (p. 248). A universalização do ensino fundamental não foi acompanhada por um projeto educacional preocupado em criar um ambiente favorável para receber todo esse contingente, com necessidades diferentes do público que até então frequentava as escolas. A evolução quantitativa do sistema escolar brasileiro se deu através de uma precária ampliação da oferta educacional, diagnosticada pela omissão ou falta de comprometimento das obrigações escolares, "expresso, entre outros fatores, pelas instalações precárias de seu ambiente físico, pela redução da jornada e multiplicação dos turnos, pela desorientação didático-pedagógica e pela baixa qualidade da formação dos professores" (Cavaliere, 2002, p. 248). De acordo com Cavaliere (2002, p. 248): 
Desafios e Dificuldades na Implementação do Programa Mais Educação

Nesse último período, firmou-se a tradição das instituições escolares omissas, cujo principal produto é a exclusão precoce de grande parte das crianças que a elas chegam. Tal situação atingiu o ápice nas décadas de 70, 80 e 90. O coroamento do ciclo de urbanização desordenada associado a políticas públicas erráticas e inadequadas (Cunha, 1995) bem como a tendente privatização do sistema, com a retirada da classe média urbana da escola pública, consolidaram a baixa qualidade prática e simbólica do sistema de educação fundamental pública.

Segundo a autora, em meio a essa realidade se esboça um processo reativo conduzido pelos profissionais das escolas, que ainda carece de elaboração política coletiva, “[...] de incorporação de um conjunto de responsabilidades educacionais, não tipicamente escolares, mas, sem o qual, o trabalho especificamente voltado para a instrução escolar torna-se inviável" (Cavaliere, 2002, p. 247). São atividades relacionadas à higiene, saúde, alimentação, cuidados e hábitos primários. Conforme Cavaliere (2002, p. 248), “[...] observa-se grande dependência afetiva de parcela importante do alunado que, muitas vezes, tem na escola e em seus profissionais a referência mais estável entre suas experiências de vida".

Os defensores da ampliação da jornada escolar, especialmente os avalistas do PME, acreditam que o aumento do tempo diário de escolarização das camadas populares pode gerar equidade no sistema educacional brasileiro. Imagens sobre a escola e seu público estão presentes nesse tipo de proposta de ampliação da jornada escolar com base no argumento que as camadas populares possuem poucas oportunidades de desenvolvimento de capital cultural em função da origem social (Bourdieu, 1998).

Em função do pressuposto da relação entre a herança de capital cultural e o sucesso escolar, a escola deve arcar com a responsabilidade, para além da instrução ordinária das disciplinas escolares, de fornecer experiências formativas e sinergia cultural que tentem cobrir as defasagens e lacunas com as quais os filhos das camadas populares chegam à escola. Outra imagem presente nas propostas de ampliação da jornada escolar aponta, de forma ambígua, para o esgotamento do atual modelo de escolarização segmentado em disciplinas, que utiliza metodologias pouco atraentes e transmite conteúdos desvinculados das experiências dos alunos. Essa imagem coloca a escola em xeque para atender as atuais demandas da sociedade, principalmente, as demandas das camadas populares.

O PME, por ser um programa de apoio à escola, pode ser encarado como uma estratégia que pretende aumentar a sinergia cultural na escola e, ao mesmo tempo, introduzir novas formas escolares e novos atores nesse espaço para transformações na dinâmica escolar tradicional. Os programas de ampliação do tempo escolar se baseiam na ideia que o contato cotidiano dos alunos com um conjunto de atividades, para além do tempo ordinário das disciplinas escolares, pode contribuir para o sucesso escolar das crianças das camadas populares.

1064 Educação \& Realidade, Porto Alegre, v. 42, n. 3, p. 1059-1079, jul./set. 2017. 
Deste modo, a ampliação da jornada escolar poderia, em tese, favorecer as famílias com reduzidas condições financeiras de arcar com os custos de atividades voltadas para formação intelectual e cultural, oferecendo esta complementação educacional dentro do espaço escolar ou em outros espaços educativos com os parceiros das escolas.

Nessa direção, a escola de tempo integral no Brasil apresenta-se como uma alternativa capaz de complementar as tarefas de competência das famílias relacionadas à socialização primária (higiene, alimentação e bons hábitos), bem como a complementação formativa com atividades de reforço escolar e de experiência cultural (esportes, literatura, artes etc.). Devemos destacar que alguns dos argumentos justificadores da escola de tempo integral se baseiam na construção de uma imagem homogeneizante das camadas populares no quadro da desigualdade social de nosso país. Com isso, esquecemos de observar como os bem-sucedidos na escola pública, oriundos das camadas populares, organizam suas estratégias de escolarização e como as escolas podem fazer a diferença no modelo escolar adotado em nossa sociedade (Andrade; Soares, 2008).

A ampliação da jornada escolar, na perspectiva da educação integral nunca muito bem definida no escopo do PME, se baseia na crença que a maior sinergia cultural pode gerar um efeito positivo em toda a escola, contribuindo para torná-la um ambiente atrativo e valorizado, proporcionando, em última instância, resultados positivos na educação dos alunos e na superação das desigualdades escolares.

\section{Métodos}

Tomamos as escolas da Rede Municipal de Petrópolis (RJ) como foco de observação da implementação do PME sendo que o trabalho de campo foi realizado no segundo semestre de 2014. Optamos por trabalhar nessa pesquisa em escala reduzida na medida em que não tínhamos bancos de dados disponíveis sobre os modos pelos quais os gestores atuam na implementação do programa. Estudos dessa natureza são necessários para realização de futuras investigações mais abrangentes sobre a implementação do PME.

O primeiro procedimento foi entrar em contato com a secretaria de educação para obter a liberação de acesso às escolas e o apoio necessário para a realização do estudo. Nesse primeiro contato recebemos uma tabela que apontava 82 escolas que ofereciam o PME, bem como o quantitativo de alunos e das oficinas por escola na época.

Recorrendo aos microdados do Censo Escolar (Inep, 2013) verificamos que o tamanho da rede no município era de 172 escolas e, aproximadamente, $48 \%$ deste total desenvolviam o PME em 2014. A partir desses números, percebemos que havia uma significativa variação entre as escolas no que se refere à cobertura do programa. Observamos escolas com um elevado número de matrículas no PME em relação ao número total de matrículas, atendendo mais de $80 \%$ dos alunos. O maior percentual de atendimento encontrado foi de $88,9 \%$. Noutra ponta, obser- 
Desafios e Dificuldades na Implementação do Programa Mais Educação

vamos escolas com baixos percentuais de atendimento com 9,5\% do total de alunos atendidos pelo PME.

A partir deste quadro de atendimento estabelecemos os critérios de seleção das escolas para o estudo. Das 82 escolas que desenvolviam o PME selecionamos seis a partir do critério de escolas que ofereciam os dois segmentos do ensino fundamental e que apresentavam alta ou baixa cobertura do PME. Escolhemos 3 escolas que apresentavam alta cobertura e 3 com baixa cobertura para entender as percepções dos burocratas no nível da rua sobre a gestão do PME em escolas que atendem diferentes contingentes de alunos. A variação no atendimento pelo PME nas escolas ficou a seguinte: para as escolas com alta cobertura, a variação ficou entre $33 \%$ e $44,8 \%$ do total de alunos; para as escolas com baixa cobertura a variação ficou entre $11,2 \%$ e $15,1 \%$ do total de alunos. O número de escolas foi definido em função dos propósitos do estudo e das condições operacionais de sua realização.

O trabalho de campo consistiu na realização de entrevistas semiestruturadas realizadas com os diretores, os professores coordenadores e os monitores do PME de cada uma das escolas. Precisamos considerar a discricionariedade dos burocratas de nível de rua, pois é de acordo com a compreensão que eles possuem acerca dos direcionamentos e objetivos das propostas, juntamente com as suas referências sociais, culturais e profissionais que será conduzida a tradução dos programas para a população (Brandolin, 2016, p. 22).

As entrevistas foram construídas com base nos seguintes blocos temáticos: adesão da escola ao PME; características da escola; recursos humanos; seleção, organização e conteúdo das oficinas; participação dos alunos; gestão e funcionamento do programa; possíveis dificuldades para o desenvolvimento do programa. As questões aos diferentes grupos foram adequadas ao tipo de função de cada entrevistado.

No total, foram realizadas 33 entrevistas (6 diretores, 6 coordenadores e 21 monitores) sendo que 32 foram gravadas com autorização prévia dos participantes. Apenas um dos entrevistados não autorizou a gravação, mas suas respostas foram anotadas. Conseguimos entrevistar quase todos os participantes do PME nas escolas selecionadas, a única exceção foram os monitores (escola-2) que estavam afastados em função da interrupção do programa por falta de verba. O material da entrevista foi categorizado a partir dos principais eixos/temas que surgiram de forma central nas falas dos entrevistados: território e escola; cuidado e assistência; gestão do PME na escola; autonomia e complementação de recursos. A perspectiva de análise adotada foi a de confrontar as percepções dos burocratas do nível de rua (os agentes escolares que atuam diretamente no PME) com os objetivos do PME e com a literatura e legislação pertinente ao objeto de estudo.

\section{Cidade Educadora, Território e a Escola}

O PME parece acumular mais prestígio em função das perspectivas teóricas que podem transformar a escola, representada em crise por

1066 Educação \& Realidade, Porto Alegre, v. 42, n. 3, p. 1059-1079, jul./set. 2017. 
diferentes motivos, do que promover, até o momento, mudanças efetivas na cultura escolar e na distribuição de oportunidades educacionais efetivas (Dyer, 2012; Fundação Itaú Social, 2015).

Um dos pressupostos do PME se baseia no movimento das cidades educadoras que pressupõe que a educação não se limita ao espaço da escola, nesse sentido, a cidade, o território e as instituições deveriam agir em cooperação com a escola na tarefa de formar cidadãos. A cidade, assim, deve tornar-se ou ser um espaço de educação e cultura que se estende à escola e essa se dirige à sociedade com uma instância orgânica da tarefa educativa. A escola, assim, deve se reorganizar para participar de uma rede mais ampla de difusão e troca de conhecimentos na vida comunitária. Esse movimento teve início nos anos de 1980 e se consolidou em 1990 com a primeira reunião das Cidades Educadoras realizada em Barcelona (Gadotti, 2006).

O PME iniciou como um programa, autodenominado, de indução da educação de tempo integral/educação integral na gestão do ministro da educação Fernando Haddad. A experiência de Nova Iguaçu (RJ) com o Programa Bairro-Escola, na gestão do prefeito Lindenberg Farias teria estimulado o ministro na época e sua equipe a ampliar essa experiência para outras prefeituras no Brasil (Moll, 2012). O Bairro-Escola teve mais eficácia na difusão de um ideal de programa integrador da escola com a cidade ou de educação comunitária do que os seus resultados apresentaram quando confrontado a uma análise que mapeou a cobertura, o desenvolvimento da intersetorialidade, a construção de um pacto comunitário no entorno das escolas, a adesão dos alunos e famílias ao turno integral e as transformações das escolas da rede a partir do referido paradigma (Lavinas; Fogaça, 2011; Moehlecke, 2015). Na mesma direção, o relatório sobre o PME da Fundação Itaú Social (2015) demonstra que o PME tem um efeito quase nulo ou inexistente no que diz respeito ao impacto do programa no desempenho acadêmico dos alunos participantes, considerando a base de dados das avaliações nacionais em Português e Matemática. Este relatório pondera que esses resultados são iniciais e este não é o único objetivo do PME, todavia, os dados para medir os demais objetivos do programa não estão disponíveis. Devemos destacar que esse programa se tornou de tal ordem uma prioridade no Governo Federal que as críticas, em geral, são imunizadas por seus defensores na arena acadêmica e política.

A questão que se apresenta é como as escolas do município de Petrópolis, observadas nesse estudo, construíram suas parcerias e desenvolveram o programa no contraturno escolar nos espaços e instituições parceiras pela cidade?

A idealização da cidade educadora esbarra na ausência de equipamentos culturais e instituições que provoquem ou sejam chamadas a provocar um movimento cultural na perspectiva de uma cidade educadora. Nossas observações no trabalho de campo mostraram que a infraestrutura disponível para o programa, na maior parte das escolas, é insuficiente tanto na escola quanto no seu entorno. As diretoras das escolas investigadas argumentam que o estabelecimento de parcerias 
Desafios e Dificuldades na Implementação do Programa Mais Educação

com outras instituições é inviável em função da localização dessas escolas no território. Assim, as oficinas ocorrem, em sua maioria, em espaços improvisados na própria escola. Apenas na escola-5 foi relatado que algumas das oficinas ocorriam no parque municipal de Petrópolis, contudo, esta prática não era realizada através de nenhuma parceria e o uso desse espaço era assistemático. Como destacaram Lavinas e Fogaça (2011), no caso do Bairro-Escola de Nova Iguaçu, o simples uso de infraestrutura municipal ou espaços públicos não pode ser considerado parceria no conceito idealizado de uma cidade educadora.

Para além dos problemas objetivos da falta de espaços e das instituições que efetivamente possam ser parceiras na dimensão de uma educação integral, outros problemas afligem os nossos burocratas no nível da rua. A diretora da escola-6 e coordenadores e monitores de outras escolas relataram ter preocupação com atividades realizadas fora do espaço escolar. A preocupação recai sobre a responsabilidade que passam a ter, principalmente, no deslocamento de crianças pequenas para outros espaços fora da escola. Nesse sentido, a parceria e participação de outros segmentos públicos se tornam fundamentais (agentes de trânsito e efetivos de segurança como guarda municipal e polícia militar), mas nem sempre possíveis. A imagem da rua como perigo e da alta responsabilidade de conduzir crianças no espaço público, não sem razão em alguns contextos e territórios, pode ser um primeiro obstáculo na construção de parcerias com o entorno da escola. Destaque-se que a maioria das escolas públicas está instalada em territórios ou bairros nos quais existem carência e ausência de equipamentos culturais e instituições que poderiam dar suporte e apoio ao PME.

No trabalho de campo encontramos oficinas do PME sendo desenvolvidas em refeitórios, pátios das escolas e em outros espaços inadequados para qualquer atividade educacional, esportiva ou cultural de qualidade. Embora esta pesquisa não tenha se dedicado a realizar observações sistemáticas das atividades desenvolvidas nas oficinas do PME, durante as visitas às escolas foi possível perceber como se dava o funcionamento de algumas das oficinas em espaços improvisados. Como exemplo, destacamos: a oficina de dança acontecendo no refeitório de uma escola; a de recreação na sala de informática repleta de computadores; a de música funcionava sem instrumentos musicais; a de jiu-jitsu no espaço de circulação da escola, isto é, localizada junto à porta de entrada. Nesse caso, o discurso da cidade educadora, da educação comunitária, se torna ineficaz diante dos inúmeros problemas de gestão das oficinas no espaço precarizado da escola e dos bairros em seu entorno.

\section{Caráter Assistencialista do PME}

Diante da distância entre os ideais do PME e o cotidiano do desenvolvimento do programa nas escolas observadas, nossos entrevistados (burocratas do nível de rua) destacaram explicitamente que o programa possui um caráter assistencialista. Foi recorrente na fala dos entrevis-

1068 Educação \& Realidade, Porto Alegre, v. 42, n. 3, p. 1059-1079, jul./set. 2017. 
tados a preocupação com a valorização da proteção das crianças que, em tese, poderiam ficar expostas aos "perigos da rua". As atividades do PME serviriam, prioritariamente, para atender as famílias que, em função das necessidades de sobrevivência, não possuem apoio familiar ou profissional para acolher seus filhos quando estes não estão na escola. A imagem dos gestores é que, para muitas famílias, o PME significa proteção e acolhimento de filhos que poderiam ficar desamparados à própria sorte em suas comunidades. As diretoras, coordenadoras e monitores indicam, em suas falas, que a função do programa está alinhada à proteção das crianças em situação de vulnerabilidade social. Vejamos as falas dos representantes das diferentes escolas sobre esse tema:

A proposta dele também é essa, é tirar da rua, então eu acho que é mesmo pra esse, que a mãe trabalha, que não tem muita assistência em casa, que precisa de um lugar... Se você vê bate direitinho porque é esse aluno que tem mais dificuldade na escola, que teria que ter o reforço (Diretora 5).

[...] eu acho que a proposta do Mais Educação em si é boa né, tirar esses alunos da rua [...] evitar que eles fiquem com o tempo ocioso e fazendo atividades a toa. A proposta é boa só que a nossa escola não tem infraestrutura pra isso, então [...] a gente fica às vezes cansada porque é muito estresse sendo que as vezes a gente não tem o apoio da família[...] (Coordenador 1).

[...]a gente ainda tem alguns alunos que não querem participar do programa, que realmente já disseram claramente: eu não quero fazer o Mais Educação, mas [...] a mãe não tem com quem deixar em casa porque precisa trabalhar e tem outros filhos menores que também estão na escola que também estão no programa e eles acabam ficando. Esses alunos [...] não se interessam, porque eles realmente não estão a fim de estar ali [...] Assim da família não tem como cuidar e prefere então deixar na escola do que deixar em casa sozinho (Monitor 1).

Os burocratas do nível da rua que entrevistamos fazem uma imagem do programa como uma forma de assistência às famílias que não possuem condições de acolher seus filhos após o turno escolar. A velha imagem que a rua é o local de perigo e de exposição a riscos para as crianças parece, por si só, justificar o programa nas falas dos seus implementadores. O aumento da inserção da mão de obra feminina no mercado de trabalho impõe que o Estado crie políticas que auxiliem as mulheres na dupla jornada, casa-trabalho (Scorzafave et al., 2001).

Poder-se-ia interpretar que a escola, na visão dos nossos entrevistados, passa a assumir o papel de redentora ao tentar minimizar os problemas decorrentes da estrutura desigual de nossa sociedade. $\mathrm{Ob}$ servemos que o debate sobre a educação compensatória, seus limites e suas possibilidades, foi um tema recorrente nos anos de 1980. Saviani argumentava na época:

Daí porque a educação compensatória compreende um conjunto de programas destinados a compensar deficiências de diferentes ordens: de saúde e nutrição, familiares, emotivas, cognitivas, motoras, linguísticas etc. Tais programas acabam colocando sob a responsabilidade da 
Desafios e Dificuldades na Implementação do Programa Mais Educação

educação uma série de problemas que não são especificamente educacionais, o que significa, na verdade, a persistência da crença ingênua no poder redentor da educação em relação à sociedade. A consequência é a pulverização de esforços e de recursos com resultados praticamente nulos do ponto de vista propriamente educacional (Saviani, 2009, p. 30-31).

A crítica de Saviani dos anos de 1980, republicada em 2009, faz certo sentido se trabalharmos com a visão de como deveria ser a escola numa sociedade mais justa e igualitária. Todavia, diante de nossa realidade social injusta e desigual, esse tipo de crítica, ainda que pertinente, cria mais impotência do que um caminho para pensar como a escola pode fazer diferença na vida daqueles que estariam, pela origem social, condenados a permanecer nas posições sociais de origem (Bourdieu; Passeron, 2013). Como lembra Cavaliere (2002) "a ampliação das funções da escola, de forma a melhor cumprir um papel sociointegrador, vem ocorrendo por urgente imposição da realidade e não por uma escolha político-educacional deliberada" (Cavaliere, 2002, p. 250). De fato, nosso sistema público de ensino, na educação básica, reflete como se deu e se dá a correlação de forças na arena política na construção de uma escola pública para todos. Os estudos no campo da sociologia da educação no Brasil continuam demonstrando como os sistemas públicos de ensino são produtores de desigualdade no interior das próprias escolas e nas formas de seleção dos alunos. Koslinski, Alves e Lange (2013) argumentam que as desigualdades sociais e educacionais brasileiras são amplas e multifacetadas. Conforme os autores, diversos estudos já se debruçaram nas diferentes formas em que as desigualdades se manifestam - seja a partir da dualidade rural versus urbano, sistema público versus privado, entre ou dentro dos sistemas públicos e/ou entre as regiões geográficas brasileiras. Destacam ainda que

[...] são variadas as dimensões ou parâmetros que são utilizados para ilustrar as desigualdades educacionais: englobando desde estudos que focalizam insumos - como a infraestrutura das escolas (Sátyro; Soares, 2007; Soares; Sátyro, 2008) e a distribuição de recursos financeiros (Pinto, 2007) - até aqueles que focalizam resultados escolares tais como proficiência, fluxo e trajetórias escolares (Koslinski; Alves; Lange, 2013, p. 1176).

O PME, de certa forma, segundo os gestores que entrevistamos, serve prioritariamente para atender as famílias que não possuem o apoio necessário para acolher seus filhos quando não estão na escola. Nesse caso, a dimensão do programa que pretende aumentar as oportunidades de sucesso escolar para as crianças que estão em situação de vulnerabilidade social se transforma em assistência e apoio às famílias.

Foi possível perceber que o PME se mostrou útil ou interessante para as crianças mais novas, matriculadas nos anos iniciais do ensino fundamental. Das 5 escolas investigadas, 4 não atendem ao nono ano e uma dessas 4 escolas não atende ao oitavo ano com o PME. A diretora da escola-1 afirmou que a ausência dos alunos nos últimos anos do ensino 
fundamental no PME se dá pela falta de interesse intrínseco no programa. Ela relatou que a participação dos alunos se dá, majoritariamente, até o sexto ano, mesmo assim em número reduzido no ano escolar de 2014. Vejamos as falas das diretoras:

Então, aí, acabou que naturalmente os maiores entraram e foram saindo e a gente teve que abrir vagas para quem realmente desejava...aí a gente atende os alunos do $1^{\circ}, 2^{\circ}, 3^{\circ}, 4^{\circ}$, alguns do $5^{\circ}$, alguns até do $6^{\circ}$ ano né, mas assim, um número muito reduzido (Diretora 1 ).

No $9^{\circ}$ ano, esse ano não teve ninguém, até porque eles já começam a ter outros cursos a tarde; muitos também vão para aquele [projeto] do menor aprendiz. [...] Do oitavo ano são poucos, deve ter uns cinco alunos. O sétimo tem pouco, o sexto tem mais (Diretora 5).

Como o PME não é compulsório, as famílias devem aderir à escola de turno integral, todavia, ficou patente nesses relatos que os mais velhos não se interessam em participar da jornada ampliada da escola de tempo integral no modelo do PME. A adesão ao turno integral também não interessa a todas as famílias atendidas pela escola pública. Devemos considerar que uma parcela das famílias prefere a manutenção de seus filhos no modelo escolar majoritariamente vigente, pois seus filhos podem, no contraturno, ter tempo para convívio familiar e social, para realização de atividades ou cursos de interesse ou, ainda, para a iniciação no mercado de trabalho como aprendiz. A diretora da escola-5 descreve as características do alunado que, em sua opinião, não tem o perfil para permanecer no PME.

Aqueles que têm uma vidazinha não conseguem, não ficam, não têm perfil. Aqueles que estão acostumados a chegar em casa, a mãe recebe e cuida e dorme de dia e vê televisão e sai com a mãe, esses não ficam. Ficam uns dois meses e pedem pra sair. Agora os outros não, os outros que se criam aí, eles ficam. Ficam, gostam (Diretora 5).

Esse tipo de percepção da escola de tempo integral foi analisado por Branco (2012) quando tratou as percepções dos pais sobre o Programa de Educação Integral de Apucarana; um dos programas que serviu de base para a construção do PME. Branco (2012) indica que os pais não visualizavam naquele programa oportunidades de ampliar vivências esportivas, artísticas e culturais dos seus filhos. No trecho a seguir o autor descreve:

Foram ouvidos quatro mães e um pai de alunos das escolas municipais. Todos afirmaram gostar muito das escolas e que seus filhos eram muito bem atendidos. Das mães ouvidas duas delas eram trabalhadoras, fora do lar, e afirmaram que ficavam tranquilas no trabalho sabendo que as crianças estavam bem cuidadas na escola. As outras duas mães que permaneciam em casa o dia todo afirmaram que gostavam muito da escola e do atendimento de seus filhos, porém achavam que o tempo integral era necessário só para as mães que trabalham. Para as que ficam em casa o dia todo, seria melhor que seus filhos não ficassem o dia todo na escola, uma vez que elas podem 
Desafios e Dificuldades na Implementação do Programa Mais Educação

cuidar deles. Da mesma opinião foi o pai que, por ser aposentado, achava que seu filho não precisava ficar o dia todo na escola, embora ele afirmasse gostar do que o filho aprendia na escola (Branco, 2012, p. 119).

A ampliação da jornada escolar se mostrou útil e compreensível por seu caráter assistencialista e não pela ampliação das oportunidades formativas para os alunos atendidos que estão em desvantagem social e cultural. Portanto, devemos destacar que a escola de tempo integral não parece ser consenso na comunidade e nem entre os gestores (Branco, 2012). Segundo a diretora da escola-1, a opinião dos pais em relação ao PME não é consensual. Para alguns dos responsáveis, segundo essa diretora, o PME acabava gerando um cansaço extra para os alunos por permanecerem o dia inteiro na escola; para outros, o programa é valorizado, tanto pelo interesse dos alunos quanto pela necessidade dos pais de terem na escola uma instituição de proteção dos seus filhos. Destacamos que os relatos sobre o cansaço dos alunos participantes do PME foi recorrente em diversos depoimentos em nossa pesquisa. A coordenadora da escola-1 e a diretora da escola-5 sugerem que deve existir um tempo e um espaço destinado ao descanso dos alunos que participam do PME. Segundo a coordenadora da escola-1, o cansaço se torna um obstáculo à participação dos alunos nas diferentes oficinas.

Sob outro prisma de análise, cabe questionar se a referida ampliação da jornada escolar, presente no PME e em outras propostas de educação em tempo integral, não estaria competindo com outras oportunidades da criança viver experiências para além da escola e da vigilância dos agentes dessa instituição. De fato, devemos questionar se esse modelo de experiência com a escola de tempo integral, na qual as atividades são mediadas permanentemente por professores, monitores e inspetores, não estaria cerceando outras experiências possíveis da sociabilidade infantil que ocorrem em outros espaços não escolares - praça, playground, rua etc. (Carvalho, 2015, p. 8).

\section{Gestão do PME na Escola: atalhos e impasses}

A ampliação da jornada escolar, com o oferecimento de atividades no contraturno escolar, utiliza como mão de obra prioritária os voluntários que devem assumir essas atividades de caráter educacional. Segundo o Artigo $1^{\circ}$ da lei $n^{\circ}$. 9.680, de 18 de fevereiro de 1998, o voluntário é aquele que exerce atividade não remunerada, prestada por pessoa física a entidade pública de qualquer natureza, ou a instituição privada de fins não lucrativos, que tenha objetivos cívicos, culturais, educacionais, científicos, recreativos ou de assistência social, inclusive mutualidade (Brasil, 1998).

A mesma lei indica no artigo $3^{\circ}$ que o voluntário poderá ser ressarcido das despesas comprovadas no exercício da atividade, sem que isto implique, como determina o parágrafo único do Art. $1^{\circ}$, em obrigações trabalhistas. O programa PME se utiliza desse enquadramento legal para contratar os voluntários que assumem as oficinas do programa. A 
escola, por intermédio da direção, contrata aqueles que estão disponíveis para atuar junto aos alunos no contraturno. Todavia, a ideia de ressarcimento das despesas pode ser considerada como renda na medida em que uma reclamação recorrente dos participantes e dos gestores é o baixo valor da remuneração. No contexto de uma sociedade desigual como a nossa, o voluntariado tem representado nesse programa uma espécie de subemprego ou estágio na medida em que a demanda de monitores é formada por universitários em formação e/ou por pessoas que assumem esse espaço como forma de complementação de renda.

Os coordenadores relataram as dificuldades de conseguirem voluntários. Esse problema incide mais sobre algumas oficinas que dependem de um mínimo de expertise no tema para ser desenvolvida, tais como: rádio escolar, horta, laboratório de ciências, reforço escolar, dentre outras. O pouco tempo de vínculo com o programa, diagnosticado para a maior parte dos monitores, pode ser um indício do tipo de problema enfrentado pelos burocratas do nível da rua. Os dados sugerem, apesar de não representativos do universo de abrangência do PME, que dos 21 monitores entrevistados, 11 possuem de 2 a 4 meses de experiência na gestão pedagógica das oficinas, 5 monitores de 6 a 9 meses e 5 com experiência entre 16 e 48 meses.

O perfil dos monitores coloca em questão o conceito de voluntário tratado pelo PME. O tempo de permanência dos monitores se contrasta com o tempo de permanência dos diretores e coordenadores que possuem uma relação trabalhista totalmente diferente com a escola e com a prefeitura. O voluntariado do PME, nos casos estudados, não é formado por pessoas engajadas num movimento social em prol da educação ou de uma sociedade solidária; os monitores pesquisados, em sua maioria, buscam nesse programa experiência e/ou alguma renda que contribua com sua sobrevivência. Ao que tudo indica, a necessidade de ter um responsável disponível, em determinado horário, para atender as oficinas, se sobrepõe a expertise que o monitor deva ter para atuar com segurança e qualidade no programa.

As condições econômicas e institucionais do PME acabam por incidir no perfil do voluntário que é jovem (até 30 anos) ou, quando passa dessa idade, possui baixa escolarização. Os 21 monitores entrevistados apresentam a seguinte distribuição em relação ao nível de escolarização: 2 com ensino fundamental completo, 5 com ensino médio, $1 \mathrm{com}$ curso técnico, 10 cursando o ensino superior, 2 com graduação completa e 1 com especialização incompleta (fora da área educacional. Nas escolas estudadas fica claro que a maioria utiliza o PME como uma oportunidade de estágio remunerado ou oportunidade de formação $l e$ arning in job, sem as obrigações formais do estágio curricular previsto nos cursos de graduação. Noutra direção, aqueles que se envolvem com o voluntariado, com baixa escolaridade e idade avançada, em geral, atuam nas oficinas que não dependem, obrigatoriamente, de formação acadêmica (capoeira, dança ou esportes).

Com base nos relatos apresentados, foi possível perceber que a rotatividade dos monitores está relacionada à falta de vínculo profissional 
Desafios e Dificuldades na Implementação do Programa Mais Educação

com o programa. Dentre os monitores voluntários, $76 \%$ dos entrevistados são enfáticos em reclamarem do baixo valor da ajuda de custo (ou ressarcimento) e da ausência das garantias trabalhistas (férias e décimo terceiro salário) por conta do tipo de contrato de voluntário que não implica essa formalização. Esse fato por si só já coloca em questão o modelo do voluntariado assumido pelo PME ao recrutar aqueles que estão em situação de insegurança econômica e social ou, no limite, possuem limitadas condições financeiras. Com isso, a ampliação da jornada escolar se dá com aqueles que não estão estabilizados no mercado de trabalho e, em alguns dos casos, estão em situação de insegurança social (Piketty, 2015).

Para além da dimensão objetiva, os monitores do PME relataram que enfrentam e sentem preconceito por uma parcela dos funcionários efetivos de algumas escolas. O PME aumenta, querendo ou não, o volume de trabalho dos funcionários das escolas e este fato acaba por criar resistências em relação ao programa. Os monitores afirmaram que, por vezes, se sentiam ignorados e enfrentavam o descaso dos funcionários. A escola aumentando a jornada escolar, mesmo que seja para parte dos alunos, aumenta significativamente a circulação e a gestão de pessoas e espaços na escola. Esse fato por si só cria problemas de gestão e segurança nas escolas, cujo espaço escolar é limitado e precarizado. Além disso, os oficineiros, por não serem de fato voluntários, no sentido do conceito da atividade, e por não possuírem uma situação estável do ponto de vista trabalhista, são representados no interior da escola como trabalhadores de segunda categoria que buscam a sobrevivência ou complementação salarial.

Soma-se a toda esta precária relação de exercício e vínculo dos monitores com o PME, a natureza das turmas compostas pelos alunos do programa. Nelas encontram-se alunos de diferentes faixas etárias, diferentes níveis de aprendizagem, interesse e maturidade, questões que seriam grandes obstáculos pedagógicos para professores com larga experiência na área da docência nas turmas regulares. Imaginemos o tamanho das dificuldades enfrentadas por monitores, alguns com idades entre 19 e 29 anos iniciando a vida acadêmica, profissional ou até mesmo sem experiência ou formação na área específica da oficina. $\mathrm{Ob}$ servemos, na fala da diretora da escola-4, a percepção de um dos gestores do programa sobre esta questão.

É outra coisa do Mais Educação que dificulta um pouco o trabalho do monitor. Numa turma de estudo regular você tem crianças de uma faixa etária específica. Mesmo que haja uma distorção na turma, o bojo ali, o grande, crianças de quatro, crianças de cinco, de seis, de sete. No Mais Educação isso é misturado né. Uma das sugestões inclusive é essa, que não sejam turmas de uma idade só, que sejam turma multisseriadas, então o monitor tem que ter um preparo pra poder atender na mesma turma, ele dá aula de desenho para uma criança que talvez nem tenha coordenação motora muito desenvolvida, em contrapartida, ele tem outro [aluno] que já é excelente (Diretor 4).

Alguns monitores indicaram a necessidade de receberem os conteúdos previamente elaborados para cada uma das oficinas. A pouca

1074 Educação \& Realidade, Porto Alegre, v. 42, n. 3, p. 1059-1079, jul./set. 2017. 
experiência somada à necessidade de atuar como professores, visão essa compartilhada por parte dos monitores, gera dificuldades pedagógicas na condução das oficinas. Esse é mais um indício que o desenho do programa acredita na potência de seus agentes diante da necessidade de educar ou ocupar os alunos no contraturno. Observemos que os agentes das oficinas reivindicam capacitação pedagógica para o exercício de suas atividades.

Outro problema que surge na fala dos monitores é a falta de aproximação com os professores das disciplinas escolares e os seus próprios colegas que atuam como monitores do PME. A maior parte dos monitores relatou não ter espaço algum para o diálogo com os professores efetivos da escola, seja sobre troca de conteúdos escolares, no planejamento de aula ou no acompanhamento dos alunos. Com isso, a integração do PME no projeto político pedagógico da escola, um dos objetivos do programa, parece não se realizar nas escolas estudadas.

\section{Complementação Financeira}

Uma questão contextualizada de forma positiva pela maior parte dos entrevistados foi a melhoria das condições de trabalho proporcionadas pelo PME. Na avaliação das diretoras, coordenadoras e monitores, o PME possibilita a escola aquisição de materiais essenciais para o desenvolvimento do ensino e gestão. A exceção foi apenas a escola-1, que, de acordo com quatro dos cinco monitores, os recursos materiais disponibilizados pelo programa eram insuficientes para o bom andamento de suas respectivas oficinas. $\mathrm{Na}$ fala, principalmente das diretoras, foi possível perceber que os materiais comprados com a verba do PME, através do PDDE, servem não só ao desenvolvimento do programa, mas a toda escola.

Eu acho excelente[...] Teve um ano que nós escolhemos hip hop, por que que nós escolhemos hip hop? Porque a gente vê aqui, o funk tá muito ligado dentro da vida deles. [...] Aí a gente falou assim: vamos escolher isso pra gente, quando acabar o hip hop a gente tem esse material pra escola. E aí tem aí, eu ainda tenho uma caixa [de som] dentro da caixa[... ]que eu nem abri [...](Diretor 2).

Eu comprei talheres, comprei uma máquina de lavar roupa com esse capital pra lavar os quimonos na escola. Então você pode fazer isso, por exemplo, se você quiser comprar uma impressora com esse capital[...] eu não comprei porque eu tenho. Você pode usar isso também pra levar os alunos pra passeios, pagar transporte. Ano passado eu levei eles no jardim zoológico pelo Mais Educação [...] Eu acho que é um programa que acrescenta em termos de verba (Diretor 5).

Neste sentido, podemos pensar no interesse das escolas em receber o PME como uma possibilidade de ter recursos extras para gerir necessidades básicas da escola. Com a escassez de recursos destinados às escolas públicas em todo o país, um programa que prevê anualmente um repasse de verbas para a aquisição de materiais se mostra como altamente funcional à gestão escolar. Os recursos advindos do PME po- 
Desafios e Dificuldades na Implementação do Programa Mais Educação

dem ser úteis ao trabalho pedagógico dos docentes e dos gestores, pois esses recursos possibilitam a aquisição de materiais duráveis e de consumo para toda a escola e não apenas para as atividades do programa. Com isso, ao quebrar uma telha na escola, por exemplo, as aulas não precisam ser interrompidas pela dificuldade de manutenção dos equipamentos escolares. Cabe destacar, no entanto, de que forma a equipe gestora da escola decide pela utilização desses recursos. Conforme o PNE (Brasil, 2014b), a expectativa é a de que, em todas as redes de educação básica, seja fortalecida a constituição de grêmios estudantis e associações de pais, assegurando inclusive, espaços adequados e condições de funcionamento nas escolas e fomentando a sua articulação orgânica com os conselhos escolares, por meio das respectivas representações. Nesse sentido, é necessário pensar, na perspectiva de uma gestão democrática e colegiada, formas de ampliar a participação das comunidades escolar e local na gestão administrativa, financeira e pedagógica das escolas públicas; e apoiar os conselhos escolares na construção coletiva de um projeto educacional no âmbito da escola, em consonância com o processo de democratização da sociedade. Os recursos do PME e de seus programas não podem estar apartados dessa discussão.

\section{Considerações Finais}

Boa parte das propostas de educação em tempo integral defende um trabalho pautado em modelos escolares baseados no tempo de permanência dos alunos nas escolas e na oferta de experiências em diferentes campos de formação social, artística, esportiva e cultural. É o que Moll (2010) chama de um sentido amplo da escola de tempo integral, alinhado aos pressupostos conceituais da educação integral e das cidades educadoras. Devemos destacar que esse termo educação integral, no bojo das argumentações, funciona mais como ideia-força, assumida como positiva, que esconde mais do que revela os significados do que seria uma concepção de educação integral. O problema é que essa ideia-força pode significar desde o simples aumento de atividades culturais para os alunos (esporte, música, teatro, artes, horta, rádio escolar, etc.), a corresponsabilidade da sociedade e da cidade com a educação até a utopia da formação integral do homem voltada para o futuro do estado-nação, nesse último caso tal concepção pode carregar os ideais totalitários que preconizam uma formação total (holística) das novas gerações comprometidas com o devir (Arendt, 1979).

Compreender os burocratas do nível de rua acerca das políticas possibilita observar como essas propostas são apropriadas e implementadas junto à população. Nesse sentido, o estudo em tela, apesar de sua pequena escala, constatou as dificuldades e o tipo de compreensão singular que os gestores do PME fazem desse programa. O desenho do PME para as escolas estudadas esbarra na objetiva dificuldade das diretoras estabelecerem parcerias com as instituições no entorno, pois as escolas podem ser consideradas, com toda a precariedade, como os melhores equipamentos culturais nas regiões onde estão instaladas.

1076 Educação \& Realidade, Porto Alegre, v. 42, n. 3, p. 1059-1079, jul./set. 2017. 
Se, entre os objetivos do PME reside a imagem da construção de um ambiente com novas possibilidades de práticas e vivenciais, o mais marcante para os burocratas do nível da rua, no desenvolvimento do PME é o caráter de assistência e proteção das crianças dos perigos da rua. Para a maior parte dos diretores, coordenadores e monitores entrevistados, o maior benefício do programa para a população estava na tarefa de cuidar das crianças que poderiam estar em situação de vulnerabilidade social após o turno escolar. Com isso, nossos entrevistados argumentam que o PME não serve para todos os alunos e, também, não atende as diferentes demandas familiares.

Outro problema enfrentado pelas diretoras e coordenadores das escolas é a alta rotatividade dos monitores. Como visto, os monitores vivem uma situação ambígua entre aquilo que se idealiza como voluntariado e suas concretas situações de vida que transformam essa atividade em fonte, complementação de renda ou uma espécie de bico que a qualquer momento pode ser abandonada diante de uma nova oportunidade de inserção no mercado de trabalho. Diante destas circunstâncias, o funcionamento do programa fica comprometido.

Por fim, o PME tem o mérito de colocar na agenda uma experiência de ampliação da jornada escolar em nível nacional, mas temos que ter a devida noção que as boas intenções podem gerar efeitos perversos se não tiverem acompanhamento e avaliação na correção dos seus rumos. No campo da educação não vale a máxima de Glauber Rocha, uma câmera na mão e uma ideia na cabeça!

Recebido em 30 de novembro de 2015 Aprovado em 21 de novembro de 2016

\section{Referências}

ANDRADE, Renato Júdice; SOARES, José Francisco. O efeito da escola básica brasileira. Estudos em Avaliação Educacional, São Paulo, v. 19, n. 41, set./dez. 2008.

ARENDT, Hannah. Entre o Passado e o Futuro. 2. ed. São Paulo: Perspectiva, 1979.

BARBOSA, Maria Ligia de Oliveira. Desigualdade e Desempenho: uma introdução à sociologia da escola brasileira. Belo Horizonte: Argvmentvm, 2009.

BOURDIEU, Pierre. Os excluídos do interior. In: NOGUEIRA, Maria Alice; CATANI, Afrânio (Org.). Escritos de Educação: Petrópolis: Vozes, 1998. P. 217-227.

BOURDIEU, Pierre; PASSERON, Jean-Claude. Os Herdeiros: os estudantes e a cultura. Tradução de Ione Ribeiro Valle e Nilton Valle. 1. ed. Florianópolis: Editora UFSC, 2013.

BRANCO, Veronica. Desafios para a implantação da Educação Integral: análise das experiências desenvolvidas na região sul do Brasil. Educar em Revista, Curitiba, n. 45, p. 111-123, jul./set. 2012.

BRANDOLIN, Fabio. O Programa Mais Educação no Município de Petrópolis. 2016, 203 f. Tese (Doutorado em Educação) - Universidade Federal do Rio de Janeiro, Faculdade de Educação, Programa de Pós-Graduação em Educação, Rio de Janeiro, 2016.

Educação \& Realidade, Porto Alegre, v. 42, n. 3, p. 1059-1079, jul./set. 2017. 
Desafios e Dificuldades na Implementação do Programa Mais Educação

BRASIL. Lei n. 9.608, de 18 de fevereiro de 1998. Dispõe sobre o serviço voluntário e dá outras providências. Diário Oficial [da República Federativa do Brasil], Brasília, DF, de 19 de fevereiro de 1998. P. 2. Disponível em: <http://www.planalto.gov.br/ccivil_03/leis/L9608.htm>. Acesso em: 2 de fev. 2014.

BRASIL. Manual Operacional de Educação Integral. Brasil, 2014a. Disponível em: <http://portal.mec.gov.br/index.php?option=com_content\&view=article\& $\mathrm{id}=16690 \&$ Itemid=1115> . Acesso em: 08 de jan. 2015.

BRASIL. Lei No 13.005, de 25 de junho de 2014b. Aprova o Plano Nacional de Educação - PNE e dá outras providências. Diário Oficial [da República Federativa do Brasil], Brasília, DF, 26 jun. 2014. Edição Extra. P. 1. Disponível em: <http://www2.camara.leg.br/comunicacao/institucional/plano-nacional-de-educacao-1>. Acesso em: 28 de jan. 2015.

PIOVESAN, Eduardo. Câmara aprova Plano Nacional de Educação; texto segue para sanção. Câmara dos Deputados. Brasília: 2014. Disponível em: <http://www2.camara.leg.br/camaranoticias/noticias/EDUCACAO-E-CULTURA/469610-CAMARA-APROVA-PLANO-NACIONAL-DE-EDUCACAO-TEXTO-SEGUE-PARA-SANCAO.html>. Acesso em: 15 de mar. 2015.

CARVALHO, Levindo Diniz. Educação (em tempo) Integral e Institucionalização da Infância. In: REUNIÃO NACIONAL DA ANPED, 37, 2014, Florianópolis. Anais... Florianópolis: Anped, 2014

CAVALIERE, Ana Maria. Educação integral: uma nova identidade para a escola brasileira. Educação e Sociedade, Campinas, v. 23, n. 81, p. 247-270, 2002.

DYER, Caroline. Pesquisando a implementação das políticas educacionais: uma abordagem de mapeamento reverso. In: BROOKE, Nigel (Org.). Marcos Históricos na Reforma da Educação. Belo Horizonte: Fino traço, 2012. P. 472-478.

FUNDAÇÃO ITAÚ SOCIAL. Avaliação econômica: Programa Mais Educação, 2015. Disponível em: <http://www.redeitausocialdeavaliacao.org.br/wp-content/uploads/2015/11/sintese_Mais_Educacao_impacto-quali_20151118.pdf>. Acesso em: 15 de nov. 2015.

GADOTTI, Moacir. A escola na cidade que educa. Cadernos CENPEC, São Paulo, n. 1, p. 133-139, 2006.

KOSLINSKI, Mariane Campelo; ALVES, Fátima; LANGE, Wolfram Johannes. Desigualdades educacionais em contextos urbanos: um estudo da geografia de oportunidades educacionais na cidade do Rio de Janeiro. Educação e Sociedade, Campinas, v. 34, n. 125, p. 1175-1202, 2013.

INEP, Instituto Nacional de Estudos e Pesquisas Educacionais Anísio Teixeira. Microdados Censo Escolar 2013. 2013. Disponível em: <http://portal.inep.gov. br/basica-levantamentos-acessar>. Acesso em: 26 de mai. 2014.

LAVINAS, Lena; FOGAÇA, Azuete. Programa Bairro Escola: o fracasso de uma boa ideia. In: ENCONTRO ANUAL DA ASSOCIAÇÃO NACIONAL DE PÓS-GRADUAÇÃO E PESQUISA EM CIÊNCIAS SOCIAIS, 35, 2011, Caxambu. Anais... Caxambu: Anpocs, 2011.

LIPSKY, Michael. Street-Level Bureaucracy: dilemmas of the individual in public service. New York: Russell Sage Fundation, 1980.

LOTTA, Gabriela Spanghero. Implementação de Políticas Públicas: o impacto dos fatores relacionais e organizacionais sobre a atuação dos Burocratas de Nível de Rua no Programa Saúde da Família. 2010. 295 f. Tese (Doutorado em Ciência Política) - Programa de Pós-Graduação em Ciência Política, Universidade de São Paulo, São Paulo, 2010.

1078 Educação \& Realidade, Porto Alegre, v. 42, n. 3, p. 1059-1079, jul./set. 2017. 
MAINARDES, Jefferson. Abordagem do ciclo de políticas: uma contribuição para a análise de políticas educacionais. Educação e Sociedade, Campinas, v. 27, n. 94, p. 47-69, jan./abr. 2006.

MARTINS, Angela Maria. O campo das políticas públicas de educação: uma revisão de literatura. Estudos em Avaliação Educacional, São Paulo, v. 24, n. 56, p. 276-299, set./dez. 2013.

MOEHLECKE, Sabrina. Programa Bairro Escola/Mais Educação: uma análise do processo de implementação no município de Nova Iguaçu-RJ. In: CAVALIERE, Ana Maria; SOARES, Antonio Jorge Gonçalves. Educação Pública no Rio de Janeiro: novas questões à vista. Rio de Janeiro: Mauad X, FAPERJ, 2015. P. 111133.

MOLL, Jaqueline. Escola de tempo integral. In: OLIVEIRA, Dalila Andrade et al. Dicionário Trabalho, Profissão e Condição Docente. Belo Horizonte: Universidade Federal de Minas Gerais/Faculdade de Educação, 2010. 1 CD ROM.

MOLL, Jaqueline. A agenda da educação integral: compromissos para sua consolidação como política pública. In: MOLL, Jaqueline et al. Caminhos da Educação Integral no Brasil: direito a outros tempos e espaços. Porto Alegre: Penso, 2012. P. 129-146.

OCDE, Organização para a Cooperação e Desenvolvimento Econômico. Pisa 2012 results in Focus. Disponível em: <http://www.oecd.org/pisa/keyfindings/ pisa-2012-results-overview.pdf $>$. Acesso em: 18 de jun. 2015.

PEREZ, José Roberto Rus. Por que pesquisar implementação de políticas educacionais atualmente? Educação e Sociedade, Campinas, v. 31, n. 113, p. 11791193, 2010.

PIKETTY, Thomas. A Economia da Desigualdade. Rio de Janeiro: Intrínseca, 2015.

SAVIANI, Dermeval. Escola e Democracia. Campinas: Autores Associados, 2009.

SCORZAFAVE, Luiz Guilherme; MENEZES-FILHO, Naércio Aquino. Participação feminina no mercado de trabalho brasileiro: evolução e determinantes. Pesquisa e Planejamento Econômico, Rio de Janeiro, v. 31, n. 3, dez. 2001.

Antonio Jorge Gonçalves Soares é professor do Programa de Pós-graduação da Universidade Federal do Rio de Janeiro (UFRJ). Líder do Laboratório de Pesquisas em Educação do Corpo-CNPq (LABEC), Membro do Grupo de Estudos e Pesquisas dos Sistemas Educacionais-CNPp (GESED), Bolsista de Produtividade CNPq e Cientista do Nosso Estado - FAPERJ.

E-mail: ajgsoares@gmail.com

Fabio Brandolin é professor de Educação Física no Instituto Benjamin Constant (IBC). Membro do Laboratório de Pesquisas em Educação do Corpo-CNPq (LABEC)

E-mail: fabiobrandolin@hotmail.com

Daniela Patti do Amaral é professora do Programa de Pós-graduação da Universidade Federal do Rio de Janeiro (UFRJ). Coordenadora do Grupo de Estudos e Pesquisas dos Sistemas Educacionais-CNPp (GESED)

E-mail: danielapatti.ufrj@gmail.com 